\section{Questión}

Periodismo / Comunicación

ISSN 1669-6581

Estética y narrativa audiovisual de Youtubers católicos

Abel Suing, Lilia Carpio-Jiménez, Andrea Sinche

Question/Cuestión, Vol. 2, N66, Agosto 2020

ISSNe 1669-6581

https://perio.unlp.edu.ar/ojs/index.php/question/index

IICom-FPyCS-UNLP

DOI: https//doi.org/10.24215/16696581e464

\title{
Estética y narrativa audiovisual de youtubers católicos.
}

\section{Aesthetics and audiovisual narrative of the catholic youtubers}

Abel Suing

Universidad Técnica Particular de Loja, Ecuador

arsuing@utpl.edu.ec http://orcid.org/0000-0002-4234-5926

Lilia Carpio Jiménez Grupo de Investigación Comunicación y Cultura Audiovisual, Departamento de Ciencias de la Comunicación, Universidad Técnica Particular de Loja, Ecuador

lilkcarpio@utpl.edu.ec https://orcid.org/0000-0002-3337-1647 
Andrea Sinche

Universidad Técnica Particular de Loja, Ecuador

acsinche@utpl.edu.ec

https://orcid.org/0000-0002-8440-9609

\section{Resumen}

Algunos youtubers altruistas procuran nuevas narraciones, es el caso de los youtubers católicos. El objetivo de este artículo es conocer la estética y la narrativa de los youtubers católicos. Se analizan cuatro youtubers católicos. Las hipótesis: 1) La estética muestra procesos de producción; y, 2) La Iglesia católica participa de forma institucional. La metodología es mixta, a través del análisis de contenido, entrevistas semiestructuradas y grupo de discusión. Se aprecia un desplazamiento lento, pero consciente para fundar experiencias de evangelización a través de YouTube.

Palabras clave: Youtuber; religión; narrativa audiovisual; contenidos audiovisuales.

\section{Abstract}

Some altruistic youtubers seek new stories, as is the case with Catholic youtubers. The objective of this article is to know the aesthetics and narrative of Catholic youtubers. Four Catholic youtubers are analyzed. The hypotheses: 1) The aesthetic shows production processes; and, 2) The Catholic Church participates in an institutional way. The methodology is mixed, through content analysis, semi-structured interviews and discussion group. A slow but conscious 
movement is observed for founding evangelization experiences through YouTube.

\section{Key words}

Youtuber; religion; audiovisual narratives; audiovisual content.

\section{Introducción}

Después del surgimiento de YouTube, en 2005, la difusión de videos y las formas de interacción entre usuarios y productores audiovisuales cambiaron. Asimismo, ocurrieron modificaciones en las expresiones, la estética y los lugares de origen de los contenidos. YouTube, que cuenta con millones de usuarios, persigue la misión de "dar voz a todas las personas y poner el mundo a su alcance" (YouTube, 2019), su trabajo, de acuerdo a la manifestación de valores de la misma compañía, responde a las libertades de expresión, de información, de oportunidades e integración, es una "plataforma mediática cuyas dinámicas la pueden ubicar en un marco de orden democrático [...] La pluralidad de informaciones hace de YouTube un recurso sin parangón en el siglo XXI" (Heredia, 2016, p.90).

Pero, en la práctica la promesa de la democratización no parece concretarse. "Los datos echan por tierra las celebraciones de la producción activa de los usuarios [el consumidor] es claramente dirigido hacia contenidos definidos por cada plataforma" (Rubiano-Pinilla, 2017, p.572). El desafío de YouTube sigue pendiente, "la difusión de contenidos audiovisuales caseros frente a las grandes cadenas televisivas y radiales" (Valderrama y Velasco, 2018, p.41).

Pese a la distancia, entre la promesa y el ejercicio cotidiano, YouTube permite a sus usuarios jugar varios roles: espectador, productor, protagonista, etc. Los 
jóvenes asumen un papel activo en esta red, es su principal plataforma para el consumo de videos y ha permitido el nacimiento de los youtubers (Fernándezde-Arroyabe-Olaortua, Lazkano-Arrillaga y Eguskiza-Sesumaga, 2018; González, 2018). Un youtuber es una persona con presencia activa en YouTube, posee una estrategia a través de la cual obtiene ingresos, configura un estilo, propone mensajes y una estética que le granjean seguidores, logra impactar en ciertos segmentos de la audiencia, en algunos casos es un líder de opinión y ha hecho de esta labor su verdadera profesión, varios youtubers superaron el ámbito del entretenimiento, evolucionaron, y hoy son prodigios masivos (Gutiérrez y González, 2018; Márquez y Ardèvol, 2018; RodríguezBreijo, Gallardo-Camacho y Sierra-Sánchez, 2018).

Por otro lado, la denominación de youtubers influencers corresponde a aquellos que movilizan audiencias más allá del ámbito digital. El éxito de un youtuber está en el equilibrio entre su especialización y el contenido comercial (HerreroDiz, Ramos-Serrano y Nó, 2016).

La presencia de jóvenes youtubers es evidente, ellos han encontrado "un espacio en el que hacerse un hueco tanto como emisores de mensajes, como de generadores de contenido de éxito, bien acogido por la comunidad virtual" (Hidalgo-Mari y Segarra-Saavedra, 2017, p.53). En YouTube los jóvenes "pasan a difundir ideas, creencias y costumbres por medio de la hibridación cultural [...] se corresponde con aquel lugar o conjunto de lugares informales en el que unas personas se afilian a otras" (Vizcaíno-Verdú, Contreras-Pulido y Guzmán-Franco, 2019, p.97).

Los youtubers se han constituido en referentes sociales de los adolescentes y jóvenes, sus mensajes impactan en la construcción de identidad (Gutiérrez y González, 2018). En este contexto, lejos del "consumo audiovisual tradicional, 
los adolescentes se decantan por un consumo de contenidos audiovisuales a demanda en el que YouTube se sitúa a la cabeza" (Fernández-de-ArroyabeOlaortua et al., 2018, p.62).

Los usuarios pueden expresar su agrado, críticas, sugerencias, ideas u otros aportes en el espacio de comentarios habilitados en cada video (Pérez-Torres, Pastor-Ruiz y Abarrou-Ben-Boubaker, 2018), éstos parecen indicar la existencia de una comunidad activa que promueve el involucramiento del público a través de los contenidos que producen (Muñoz, 2018). Independientemente de la ayuda "que hayan tenido algunos youtubers, está claro que el mérito de conectar con el público ha sido suyo. La cuestión es saber si durará el idilio con su público y si sus ingredientes mágicos resistirán la profesionalización" (Meseguer, 2016, p.91).

La publicación de videos en YouTube que en muchas ocasiones inicia como una afición, se convierte en un negocio de éxito en el que cada vez más personas ven la posibilidad de ganarse la vida (Hidalgo-Mari y SegarraSaavedra, 2017). Las industrias culturales obtienen sus ingresos de la venta de bienes y servicios estandarizados, en su elaboración deben cubrir altos costos fijos, además llegan a los consumidores a través de limitados canales de distribución, en cambio los youtubers "suben sus productos a la plataforma de Internet. Un gran número alcanza rápida visibilidad y algunos consiguen dinero e influencia. Los más exitosos trascienden las redes digitales y expanden su trabajo a espectáculos" (García-Canclini, 2018, p.94).

Pero, parece que YouTube replica las etapas de Internet en tanto avanza, de un servicio que se provee de forma gratuita, a la venta de mejores y mayores opciones a través de la oferta y demanda de mercado, pero sobre todo por "su gradual institucionalización o evolución desde un medio de contenido amateur 
a uno dominado por contenidos comerciales generados profesionalmente. Si bien los youtubers emergentes y el contenido amateur no desaparecerían, tendrían posiciones cada vez más marginales dentro de la plataforma" (Valderrama y Velasco, 2018, p.42), ello implicaría un cambio de estética, de las formas domésticas y personales hacia los cánones de los grandes estudios y las lógicas del cine y la televisión.

La puesta en escena de un vídeo implica "entrelazar imagen y guion; es decir, estética y contenido" (Manso, Ezquerra, Burgos y Mafokozi, 2019, p.13), su intencionalidad puede ser educativa, didáctica, informativa o publicitaria y además cumplir funciones sociales, de interés privado o de denuncia política (Rubio, 2017), para cualquier fin requiere construir narraciones acordes con el medio de transmisión, por ejemplo, para entornos virtuales será necesario "crear vídeos más cortos o versiones menos extensas de las piezas originales para redes sociales [...] y plataformas de Internet" (Rajas, Puebla-Martínez y Baños, 2018, p.319).

La evolución del videoclip deja ver el cambio en la estética del formato audiovisual empleado en redes sociales. "Desde sus inicios en la década de 1980, con su punto más alto en la década de 1990 y ahora con su transformación en la era de YouTube, el videoclip se ha catalogado como el referente estético de toda una generación" (Roncallo y Uribe-Jongbloed, 2017). YouTube aporta el entorno adecuado para crear recursos digitales en formato audiovisual (Varela, 2016). La "cantidad de reproducciones de plataformas de vídeo online como YouTube, demuestra que no se trata de un formato menor en el conjunto de la producción audiovisual y que adquiere un protagonismo insólito en Internet" (Pérez y Rodríguez-López, 2017, p.151). 
El videoclip se anuncia como "la esencia misma de esta nueva cultura globalizada, sin un reconocimiento específico de sus características estéticas" (Roncallo y Uribe-Jongbloed, 2017), es decir en formas originales, no convencionales. La narrativa audiovisual en YouTube no exige la calidad broadcast, demanda innovación para jugar "con todas las posibilidades del lenguaje de una manera creativa y ello cuestiona esa necesidad de limpieza y resolución de la imagen" (Pérez-Rufí, 2018, p.301) a través de la cual han llegado la mayoría de producciones audiovisuales del mainstream norteamericano.

En el videoclip, "el componente visual pretende impactar al espectador, mantener su atención, invitar a la repetición del visionado de la pieza y, en definitiva, seducirlo" (Pérez, 2017, p.227), por ello su empleo concurrente en las industrias de la música, la moda y la publicidad sirvió para "sustituir o superar la fruición directa de la música en vivo, con un reemplazamiento de su recepción colectiva (en el concierto) por la doméstica e individual en una pantalla" (Gaona-Pisonero y Sedeño-Valdellós, 2018, p.118).

El sector de la moda se apoya en influencers para que, a través de "vídeos caseros de corta duración, escasa inversión en producción y una estética amateur y juvenil [...] enseñe[n] sus compras o adquisiciones a sus seguidores/as mientras habla[n] frente a la cámara de vídeo con un tono informal y desenfadado" (Vicente-Fernández, Vinader-Segura y GallegoTrijueque, 2019, p.84). Éstos videos triunfan, entre otros motivos, gracias a una "estética informal y casera, que dotan de ritmo, dinamismo y espontaneidad" (Vicente-Fernández, et al., 2019, p.95).

YouTube se alimenta de la "difusión de contenido amateur, grabado con tecnologías de amplia difusión, con escasa presencia de medios de 
comunicación tradicionales" (Gallardo-Camacho, Trujillo Fernández y Jorge, 2018, p.33), por ejemplo, los videos de varios movimientos sociales revelan que "la producción es espontánea no planificada, presenta inestabilidad de encuadre, calidad de imagen y sonido deficientes, espacio fotográfico negativo, ausencia de continuidad y coherencia espacial y falta de articulación narrativa" (Mateos y Sedeño, 2018, p.50). Los youtubers laboran con estética amateur y un estilo confesional en sus contenidos, han creado sus marcas personales y comunidades de seguidores (Elorriaga y Monge, 2018).

Cuando aún se vive una etapa de masificación de las estéticas en YouTube, los infuencers proyectan que "los futuros usuarios, capaces de asimilar grandes cantidades de información, ya están condicionando lo que parece ser una evolución hacia un formato que incorpora muchos más indicadores y elementos gráficos" (Zomeño y Blay-Arráez, 2017, p.1190).

La estética, creativa o no, y el uso de las narrativas digitales, confluyen en la figura del youtuber, quien "debe atender a su responsabilidad social, es decir, a cómo influye o impacta su contenido en la sociedad o en determinado grupo social [es decir] la estética de su propuesta" (García y Gil, 2018, p.181).

\section{Propósitos}

Hay youtubers que hablan de videojuegos, de temas cómicos, de maquillaje, cocina "y todo tipo de videos alternativos para una audiencia [...] que parece cansada de la televisión y sus restricciones" (Blanco, 2015, p.80). Existen además los youtubers altruistas, aquellos que procuran nuevas ópticas e innovadoras formas de comentar los temas clásicos y los grandes retos sociales, ingresan aquí los expertos en enseñanza, salud y, entre otros, los youtubers católicos. 
Vale mencionar que los católicos constituyen uno de los colectivos religiosos de mayor trayectoria, están presentes en todos los continentes y de acuerdo al anuario estadístico de la Iglesia el $17,67 \%$ de la población mundial es católica (Agenzia Fides, 2018), por ello es relevante la exhortación del líder de este culto, el Papa Francisco, para el uso de las nuevas tecnologías, "abrir las puertas de las iglesias significa abrirlas asimismo en el mundo digital" (Santo Padre, 2014).

Existen casos exitosos del empleo de los medios tradicionales como la radio, la prensa y la televisión para transmitir mensajes evangélicos, pero no hay experiencias trascendentales a través del ciberespacio, incluso en casos de notoriedad como ocurre con los "Youtubers latinoamericanos, hasta el momento la literatura académica no ha prestado gran atención a este fenómeno" (Valderrama y Velasco, 2018, p.42), igual sucede en otros países (Rodríguez-Breijo, et al., 2018).

Los youtubers, por las implicaciones señaladas, configuran un espacio importante para investigar las estéticas y narraciones, particularmente en comunidades religiosas como la católica que tienen ricas tradiciones culturales en la difusión de sus mensajes. El objetivo de la investigación es comparar la estética y la narrativa de los youtubers católicos respecto a las características predominantes de calidad doméstica e informalidad.

Se analizan los contenidos de cuatro youtubers católicos, dos provenientes de América y dos de Europa, continentes de referencia para el culto, el primero con gran mayoría de practicantes y el segundo donde está el Vaticano, la sede de la Iglesia católica. Las hipótesis son: 1) La estética empleada por los youtubers católicos no responde a una lógica de informalidad y espontaneidad sino a cuidados procesos de producción; y, 2) La Iglesia valora de forma 
positiva los medios sociales, busca vías para participar en YouTube pero de forma institucional.

\section{Metodología}

La metodología es mixta, cuantitativa y cualitativa, en razón de la tendencia de complementariedad presente en las ciencias sociales, se procura un procedimiento de triangulación cuyos análisis garanticen la calidad de los resultados (Cascante, 2011; Donolo, 2009). Las técnicas y herramientas usadas son análisis de contenido, entrevistas semiestructuradas y grupo de discusión. Se realizó un estudio exploratorio en la misma plataforma audiovisual a partir de las palabras "youtubers" y "católicos", luego con las categorías "este año" y "relevancia”. El resultado permitió seleccionar los casos que cumplen con los criterios de identidad, actividad e impacto, la explicación de cada categoría es la siguiente:

- "Identidad digital del canal: posee diseño e identidad visual, una firma o un logotipo. Existe la descripción del canal y se manifiesta la identidad católica. Posee información para contacto. Hay un tráiler del canal. El autor tiene un papel protagónico en los videos.

- Actividad y participación: el video muestra un proceso de producción. La frecuencia de publicación es de mínimo un mes.

- Impacto en la audiencia, medido por números de suscriptores, visualizaciones y comentarios, además de la presencia de otras redes sociales" (Arévalo, 2017).

El corpus de estudio está constituido por 12 videos, 3 videos por cada uno de los cuatro youtubers católicos, dos de América y dos de Europa, que presentan mayores reproducciones durante el último trimestre de 2018 . El 
análisis de contenido está sustentado en la propuesta de Orlando Gonzáles (2018) sobre características morfológicas, sintácticas estructurales y semánticas, para lo cual se analiza desde la estructura de la narrativa audiovisual y la estructura argumental. Los casos seleccionados son el canal Padre Reginaldo Manzzotti, de Brasil; el canal LizziesAnswers, de Estados Unidos de América; el canal Smdani, de España; y, el canal Langusta na palmie, de Polonia.

Los expertos entrevistados, en abril de 2019, fueron cinco, provienen de España, Brasil, Ecuador e Italia, responden a los siguientes perfiles: investigador en educomunicación, docente universitario en comunicación, especialista en filosofía y teología, diplomático del Vaticano; y, animador de grupos juveniles católicos. En el grupo de discusión intervinieron diez participantes: cinco hombres y cinco mujeres, de edades comprendidas entre 14 y 57 años, de diferentes grupos éticos y con distintas ocupaciones: estudiantes, ama de casa, docente, comerciante, médico, obreros.

\section{Resultados}

\begin{tabular}{|l|l|l|l|l|}
\hline YouTuber: & $\begin{array}{l}\text { Reginaldo } \\
\text { Manzotti }\end{array}$ & $\begin{array}{l}\text { Lizzie Estrella } \\
\text { Reezay }\end{array}$ & $\begin{array}{l}\text { Daniel } \\
\text { Pajuelo } \\
\text { Vázquez }\end{array}$ & $\begin{array}{l}\text { Adam } \\
\text { Szustak }\end{array}$ \\
\hline Edad: & 49 años & 24 años & 41 años & 40 años \\
\hline Formato: & Videoblog & Videoblog & Videoblog & Videoblog \\
\hline Suscriptores: & 82.8985 & 20.7835 & 44.3455 & 44.1812 \\
\hline $\begin{array}{l}\text { Nombre del } \\
\text { canal: }\end{array}$ & $\begin{array}{l}\text { Reginaldo } \\
\text { Manzotti }\end{array}$ & LizziesAnswers & Smdani & $\begin{array}{l}\text { Langusta na } \\
\text { palmie }\end{array}$ \\
\hline
\end{tabular}




\begin{tabular}{|l|l|l|l|l|}
\hline País: & Brasil & $\begin{array}{l}\text { Estados Unidos } \\
\text { de } \\
\text { Norteamerica }\end{array}$ & España & Polonia \\
\hline $\begin{array}{l}\text { Inicio } \\
\text { actividad: }\end{array}$ & $\begin{array}{l}\text { Enero de } \\
2014\end{array}$ & Junio de 2010 & $\begin{array}{l}\text { Mayo de } \\
2006\end{array}$ & $\begin{array}{l}\text { Diciembre de } \\
2012\end{array}$ \\
\hline Reproducciones: & 107.969 .645 & 210.777 & 19.411 .513 & 189.838 .043 \\
\hline
\end{tabular}

Tabla 1. Datos básicos de los canales, al 28 enero de 2019.

\section{Fuente: YouTube. Elaboración propia}

El canal del sacerdote Reginaldo Manzotti tiene un formato de transmisión en vivo, muestra celebraciones religiosas, presenta interacción al responder a los comentarios. Manzotti aparece en actitud amable, sonriente, usa vestido negro y camisa blanca. La escenografía muestra íconos católicos, hace uso de la pantalla dividida. En la narrativa audiovisual, la composición, está centrada en el personaje. Hay variedad de planos: general, medio largo, corto, detalle y primer plano, además existen recursos de accesibilidad como insertos de lenguaje de señas. Dos piezas tienen movimientos de cámara: paneo, tilt up. El ángulo del encuadre va de normal a picado.

El sonido utilizado es diegético y extradiegético, pero también voz off y música de fondo para las citas bíblicas. Se distingue una secuencia lineal en el montaje. Para segmentar usa un logotipo, conjuntamente, códigos visuales en diferentes colores. La iluminación es artificial en ambientes internos, y natural en externos. En la estructura argumental se distingue un proceso de preguntasrespuestas, en los dos últimos videos el sacerdote responde a temas tabú como el espiritismo. Un video corresponde a la grabación de un evento 
realizado en la Arquidiócesis de Fortaleza, Brasil, tiene la mayor reproducción, pese a su duración de 5:30:24.

Lizzie Estrella Reezay presenta una narrativa formal, utiliza un formato de videoblog para compartir su experiencia al convertirse en católica, lleva una actitud amable y expresiva frente a sus seguidores. Utiliza vestimenta casual juvenil. En la composición escénica destacan elementos alusivos a la religión católica como la imagen de Jesús o cruces en la pared. La narrativa audiovisual se centra en los relatos de la youtuber pero también comparte entrevistas, hay una composición abierta. Usa planos general, medio, americano, primero y contraplano. Los movimientos de cámara: fija, zoom in y zoom out. El ángulo de encuadre va de normal a picado. En la transición de la imagen usa barrido y cortinillas.

Hay sonidos diegéticos y extradiegéticos, además uso de campanillas para las explicaciones. El montaje es lineal: una introducción, nudo del tema y conclusión. Se observan códigos visuales como textos e imágenes mientras explica los temas, además del logotipo del canal. También hay imágenes digitales. La iluminación es artificial, los videos son realizados en ambientes internos. En el análisis argumental se destaca la forma de abordar los temas, a través de una perspectiva paradójica, tomando en cuenta razones contrarias a sus convicciones, de esa forma llama la atención de sus seguidores. Hay interacción con sus seguidores al responder a sus preguntas y presentar los obsequios recibidos.

En su canal el sacerdote Daniel Pajuelo Vázquez hace una retrospectiva de actividades. Es amable, sutil y respetuoso al exponer sus criterios, su mensaje lo emite desde la perspectiva católica y humanística. Usa vestimenta común. En la composición escénica usa imágenes creadas por computadora, logotipo y 
elementos católicos. Utiliza el formato de videoblog, analiza videos de tendencias musicales de diferentes géneros y productos audiovisuales de youtubers que tratan temas religiosos.

La composición de la narrativa audiovisual está centrada en el personaje, emplea la regla de tercios y la pantalla dividida para mostrar los videos que examina. Los planos utilizados son: medio, medio corto, primer y primerísimo primer plano. Los movimientos de cámara: sobre el eje, zoom out y zoom in. El ángulo de encuadre va de picado a normal. El sonido es extradiegético, ambiental y hay voz off al inicio y final. El montaje es lineal, en la transición de imágenes se aplica cortinillas y barridos. Se observan códigos visuales como texto de color, fotografías, imágenes digitales y la inclusión de fragmentos de videos anteriores. La iluminación es artificial. La narrativa argumental consiste en relatos de doble sentido, contradicción e hipérbole, incluso en los títulos se observan paradojas. Al inicio explica el motivo del tema, sugerido por los seguidores, luego atiende dudas de videos populares desde la perspectivas teológica y humana.

El youtuber Adam Szustak OP utiliza un formato de videoblog, compara temas católicos con películas de estreno en Polonia. Se presenta sonriente y carismático, viste común. En ningún video emplea elementos de la Iglesia católica. Se observan diferentes escenografías en videos grabados en el día y en la noche. En la composición de la narrativa audiovisual el personaje es el centro de interés. Emplea la regla de tercios. Hace uso de cámara subjetiva, además paneo, rotación, till down. Los planos son panorámicos, general, medio y primer plano. El ángulo de encuadre es picado y contrapicado. Usa música extradiegética en inglés y diferentes efectos sonoros. El montaje es lineal. En los códigos visuales usa su logotipo animado, caracteres textuales de color y 
sobreimpresiones. La iluminación es ambiental en exteriores y artificial en interiores. La narrativa argumental parte de preguntas paradójicas, usa recursos lingüísticos como metonimia, paradoja y comparación. Refiere películas de estreno e introduce textos católicos para reflexionar, culmina con un mensaje positivo hacia sus seguidores.

Opiniones de expertos

Las entrevistas permitieron profundidad sobre la estética. Los expertos entrevistados son los siguientes:

\begin{tabular}{|l|l|l|}
\hline Nombre & Función & País \\
\hline Denis Renó & $\begin{array}{l}\text { Director Académico de la Cátedra } \\
\text { Latinoamericana de Narrativa } \\
\text { Transmedia y miembro del Media } \\
\text { Ecology Association (EEUU). }\end{array}$ & Brasil \\
\hline Julio Parrilla & Misionero y Obispo católico & $\begin{array}{l}\text { España- } \\
\text { Ecuador }\end{array}$ \\
\hline $\begin{array}{l}\text { Andrés } \\
\text { Carrascosa }\end{array}$ & $\begin{array}{l}\text { Nuncio Apostólico en Ecuador - } \\
\text { Delegado de la Santa Sede del } \\
\text { Vaticano }\end{array}$ & Vaticano- \\
\hline $\begin{array}{l}\text { Ignacio } \\
\text { Aguaded }\end{array}$ & $\begin{array}{l}\text { Catedrático de la Universidad de } \\
\text { Huelva }\end{array}$ & España \\
\hline $\begin{array}{l}\text { Geovanny } \\
\text { Pazmiño }\end{array}$ & $\begin{array}{l}\text { Obispo de Ambato Responsable } \\
\text { de la Pastoral Juvenil Nacional } \\
\text { del Ecuador }\end{array}$ & Ecuador \\
\hline
\end{tabular}

Tabla 2. Datos informativos expertos 


\section{Fuente: elaboración propia}

"El youtuber tiene su estética propia, trabaja básicamente con la proximidad, como si fuese un amigo. La esencia de la estética del youtuber ha sido creada por ellos mismos" (D. Renó, comunicación personal, 15 de abril de 2019). En el futuro la estética youtuber permanecerá,

"el formato se transforma, pero no va desaparecer porque es algo que la gente siempre quiso hacer, sin embargo, no existían condiciones. Ahora tenemos nuestro canal y cámaras, podemos grabar con nuestro teléfono celular y con buena calidad, lo que puede ocurrir es un cambio de plataforma. Yo estoy mirando muchas cosas de video, pero en Instagram, la esencia es que cualquier persona puede crear su propio canal y sus propias narrativas, sus historias" (D. Renó, comunicación personal, 15 de abril de 2019).

El youtuber habla para su público, tiene los elementos que lo identifican, "no está preocupado de hacer las cosas con protocolos formales porque a su público así le agrada" (D. Renó, comunicación personal, 15 de abril de 2019).

Desde el ángulo del ejercicio sacerdotal y la administración pastoral se señala que vivir de espaldas a las nuevas tecnologías es vivir fuera de la realidad. "La Iglesia siempre ha valorado profundamente cualquier sistema de comunicación y lo ha utilizado. Hoy los jóvenes socializan fundamentalmente a través de las redes sociales, mal haría la Iglesia si no estuviera presente precisamente en las redes sociales" (J. Parrilla, comunicación personal, 19 de abril de 2019).

Uno de los entrevistados señaló que el Papa Benedicto XIV manifestó que las redes sociales son la nueva frontera de la evangelización, pero "pueden vehicular pornografía o una experiencia de Dios, ahí está el desafío, conocer las tecnologías y saber qué vehiculamos. Como Iglesia tenemos la 
responsabilidad de transmitir una experiencia de Dios" (A. Carrascosa, comunicación personal, 25 de abril de 2019), pese a este riesgo "la presencia de sacerdotes en YouTube es muy positiva, [aunque] siempre está el riesgo de la banalización y no siempre hay una legislación clara que controle lo difamatorio. La ética también hay que aplicarla a YouTube" (J. Parrilla, comunicación personal, 19 de abril de 2019).

Respecto a la calidad de los contenidos de YouTube se señaló que "no son buenos ni malos, son siempre neutros. El énfasis hay que ponerlo en las audiencias. No podemos decir que los youtubers tengan contenido nocivo. Si los que reciben el contenido no tienen madurez esos contenidos pueden ser perversos" (I. Aguaded, comunicación personal, 4 de abril de 2019), por esta razón "la Iglesia está capacitando a los animadores y coordinadores con mayor grado de responsabilidad en el uso de estos medios para la evangelización" (G. Pazmiño, comunicación personal, 21 de abril de 2019).

Las tecnologías de comunicación deben estar al servicio de "la promoción del hombre, de la humanización de la vida porque no suplen la condición humana. Nunca hemos tenido tantos medios de comunicación y nunca hemos vivido en tanto individualismo y en tanta soledad. Una relación de carne y hueso te exige un compromiso personal, de diálogo, un compromiso ético que no corresponde al encerramiento en el cual mucha gente vive" (J. Parrilla, comunicación personal, 19 de abril de 2019).

\section{Voces ciudadanas}

Finalmente, en el grupo de discusión se debatió en respuesta a la pregunta ¿Es conveniente utilizar YouTube como medio de transmisión de mensajes religiosos, o para evangelizar? Los puntos centrales de las intervenciones son: 
- Participante 1: No, porque YouTube es una plataforma con fines diferentes a los religiosos, además para evangelizar es necesaria la cercanía, no a través de un computador.

- Participante 2: Sí, a la gente le gustan diferentes temáticas, hay personas a las que les interesan los mensajes religiosos.

- Participante 3: La evangelización utiliza todos los medios a su alcance. Esta vía tiene gran cobertura, así que sí es una buena idea, pero con análisis previo y mucha cautela.

- Participante 4: Sí, se puede decir todo lo que se quiera y llegar a un público ilimitado.

- Participante 5: Sí, es fácil de buscar y, por lo general, los mensajes son buenos, considero a YouTube un medio favorable para emitir mensajes católicos.

- Participante 6: No. YouTube es un espacio social donde se mezclan culturas, no religiones, entonces la religión generaría pocas visitas. La mayoría buscamos videos divertidos.

- Participante 7: Yo creo que no. YouTube es una plataforma de entretenimiento y no para asuntos religiosos.

- Participante 8: Cualquier medio es apto para repartir el mensaje de Dios, además hay que buscar que los niños sientan cercanía con Dios, lo mejor es adentrándonos en los dispositivos y medios que ellos usan y ven.

- Participante 9: No creo que YouTube esté para subir esa clase de cosas, pocos buscan ese tipo de temas ahí, sino en la Biblia, con otras personas o en los templos. Sin embargo, en radios y televisión si deberían crear programas para que se nos hagan interesantes. 
- Participante 10: Sí, deberían repartir información por este medio con la condición de que la persona domine el tema, debe considerarse que al evangelizar también se está educando.

Aunque algunos participantes consideran que YouTube no es el medio adecuado para los mensajes religiosos. La mayoría de los participantes consideran que si es un medio apto para evangelizar y educar, principalmente a los más jóvenes quienes son los mayores usuarios de esta red social.

\section{Discusión y conclusiones}

Los cuatro youtubers católicos evidencian el manejo adecuado de los recursos audiovisuales, cuidan la producción de los videos, aprovechan las ventajas del lenguaje audiovisual. El formato utilizado es, principalmente, el videoblog.

Reginaldo Manzotti trabaja una estructura lineal, usa planos característicos de la narrativa televisiva, el sonido es claro y definido, aprovecha caracteres en diferente color, emplea una imagen corporativa unificada con todas sus redes sociales. En sus videos maneja un formato de preguntas-respuestas.

Lizzie Reezay usa diferentes códigos visuales, sonoros, estéticos, textuales y flexibilidad en los recursos lingüísticos. Daniel Pajuelo Vázquez analiza videos musicales y piezas audiovisuales de otros youtubers, tiene una composición estética caracterizada por la regla de tres tercios, sobresale el amplio uso de códigos visuales y sonoros; utiliza elementos lingüísticos. Los trabajos de Adam Szustak presentan aspectos sintácticos, expresivos y lingüísticos, destaca la comparación entre películas, temas de coyuntura y mensaje católicos para extraer sus cualidades. 
En cuanto a la estructura formal, los youtubers exhiben un orden lineal: introducción, nudo y desenlace, su actitud es positiva, proactiva, sus vestuarios son casuales, no se los identifica con la ropa formal religiosa. Los escenarios cuentan con iconos religiosos, se exteriorizan tanto en espacios internos como externos. En la estructura narrativa audiovisual los ángulos de cámara son normal, picado y contrapicado, los movimientos son zoom in y zoom out, paneo, tilt up; los planos más empleados: medio corto, plano medio, plano detalle y primer plano.

Los códigos sonoros se caracterizan por sonidos diegéticos y extradiegéticos, voz off, sonidos ambientales y otros efectos que puntúan las explicaciones de los temas. El montaje, principalmente, es una secuencia lineal, una continuidad lógica a lo largo del video. Los códigos visuales son variados como fotografías, textos o caracteres de color, logotipos, gráficos, efectos visuales, particularmente la transición de imágenes como cortinillas o barridos. La iluminación es artificial en espacios internos con tonalidades cálidas, dirigidas al personaje y natural cuando son grabaciones en ambientes externos.

La estructura argumental gira alrededor de temáticas religiosas, desde diferentes perspectivas buscan relacionar al catolicismo en sus productos audiovisuales. Los temas van desde las razones para ser católicos hasta la coyuntura de la cultura popular, siempre tratados con sigilo y respeto.

De acuerdo a las opiniones expresadas en el grupo de discusión la mayoría de los participantes consideran que YouTube puede ser un medio para difundir mensajes católicos, sin embargo, si hay quienes difieren ya que estiman que el tema no tiene cabida en una red social. YouTube requiere de los aportes de los usuarios y excepto las regulaciones legales acoge múltiples contenidos, puntos de vista y corriente ideológicas, por lo que no existiría restricción para proponer 
canales y mensajes católicos o de otros credos, es una opción tratada con respeto y precisión.

La capacidad de una persona para manifestar sus opiniones por cualquier medio es un derecho esencial, que también se cumple a través de la plataforma YouTube. Transmitir mensajes religiosos a través de YouTube es una expresión del derecho a la comunicación conforme lo establece el Art. 19 de la Declaración Universal de Derechos Humanos. La red social de videos está al servicio del público, la mayoría de sus contenidos están abiertos, por lo tanto, la evangelización católica tiene a su disposición una herramienta para amplificar su alcance.

Las hipótesis son aceptadas. La estética empleada por los youtubers católicos no responde a una lógica de informalidad y espontaneidad sino a cuidados procesos de producción audiovisual. Sobre la base del análisis de contenidos las narraciones y las estéticas propuestas por los youtubers católicos están próximas a las formas del broadcast televisivo, son el resultado de protocolos de planificación, calidad audiovisual y discursos validados por las industrias audiovisuales, aunque ello podría constituirse en un factor positivo en la transición de YouTube hacia ofertas de pago donde se exhiben contenidos de corte profesional.

Las estéticas de los youtubers católicos están alejadas de la espontaneidad, la informalidad y la dinámica amateur que caracteriza al sector, pero no en contraposición a la voz de los expertos que postulan la proximidad como clave de futuro para mantener los vínculos entre los youtubers y las audiencias, en este caso las comunidades católicas.

Se aprecia un desplazamiento lento, pero consciente de la Iglesia católica para fundar experiencias de evangelización a través de YouTube. Las premisas de 
este movimiento están en las directrices de los Papas Benedicto y Francisco, y en las orientaciones de los administradores religiosos que buscan estar presentes en los medios de comunicación actuales para estar junto a sus feligreses.

Llama la atención que la edad promedio de los youtubers estudiados sea de 39 años, porque el público que mayor consume videos son adolescentes y jóvenes, pero se explicaría porque los temas abordados van desde lo coyuntural hacia lo filosófico y teológico, además las audiencias de YouTube manifiestan necesidades de filiación, contacto, amistad y, desde esta perspectiva, es mejor que los interlocutores sean personas maduras y formadas en valores sociales y cívicos.

La Iglesia estima de forma positiva a los medios sociales, busca vías para participar en YouTube, pero de forma institucional. Las voces de los ciudadanos expuestas en el grupo de discusión reflejan la tradición con la que se tratan y conservan los ritos y la jerarquía. Las vías convencionales de evangelización se mantienen en parroquias, provincias y en la estructura de la Iglesia católica, a pesar de aquello y frente a la irrupción global de las redes sociales se inicia un camino hacia la liturgia religiosa en Internet. Queda para siguientes investigaciones estudiar los diálogos entre youtubers y audiencias para determinar temas, prioridades y niveles de interacción en los espacios abiertos de las redes sociales. Además, las categorías de consumo que propone YouTube pueden segmentar a los feligreses entre quienes tienen acceso a unos $u$ otros contenidos, a una $u$ otra forma de interpretar el evangelio.

\section{Bibliografría}


- Agenzia Fides. (2018). Las estadísticas de la Iglesia Católica 2018. Recuperado en: http://www.fides.org/es/stats

- Arévalo, A. (2017). Propuesta metodológica para el análisis de YouTube y su relación con los movimientos sociales. Actas del III Congreso Internacional Move.Net sobre movimientos sociales y TIC. Sevilla: Universidad de Sevilla.

- Blanco, L. (2015). Youtubers: celebridades de la red. Debates IESA, 20(4), 80.

- Cascante, J. (2011). Métodos mixtos de investigación. España: UNED Recuperado de http://repositorio.uned.ac.cr/reuned/handle/120809/390

- Donolo, D. (2009). Triangulación: Procedimiento incorporado a nuevas metodologías de investigación. Revista Digital Universitaria. Recuperado de: http://www.revista.unam.mx/vol.10/num8/art53/art53.pdf

- Elorriaga, A.; y Monge, S. (2018): La profesionalización de los Youtubers: el caso de Verdeliss y las marcas. Revista Latina de Comunicación Social, 73, 37-54. Doi: 10.4185/RLCS-2018-1244.

- Fernández-de-Arroyabe-Olaortua, A.; Lazkano-Arrillaga, I.; y EguskizaSesumaga, L. (2018). Nativos digitales: Consumo, creación y difusión de contenidos audiovisuales online. Comunicar, 26(57), 61-69. https://doi.org/10.3916/C57-2018-06

- Gallardo-Camacho, J.; Trujillo, F.; y Jorge, A. (2018). El individualismo, como estrategia improvisada en la dispersión de vídeos yihadistas en YouTube. Revista Latina de Comunicación Social, (73), 19-36. https://doi.org/10.4185/RLCS-2018-1243 
- Gaona-Pisonero, C.; y Sedeño-Valdellós, A. (2018). Paisaje-CuerpoMúsica en el videoclip musical y el videoarte actuales. Caracteres: Estudios culturales y críticos de la esfera digital, 7(2), 110-138.

- García-Canclini, N. (2018). Cómo investigar la era comunicacional del capitalismo. Desacatos, (56),90-105. Recuperado de http://search.ebscohost.com/login.aspx?direct=trueydb=sxiyAN=1287686 44ylang=esysite $=$ eds-live

- García, F.: y Gil, F. (2018). Youtubers, mundos éticos posibles. (Spanish). Index.Comunicacion, 8(2), 151-188.

- González, O. (2018). Análisis de la narrativa audiovisual de los Youtubers y su impacto en los jóvenes colombianos. (Tesis doctoral). Doctorado Interuniversitario de Comunicación, Universidad de Málaga. Málaga, España. Recuperado de: http://www.doctoradocomunicacion.es/tesis.php

- Gutiérrez, A.; y González, A. (2018). Educación mediática «aumentada» para la interacción y participación en entornos virtuales. Análisis de una comunidad de Pokémon Go en YouTube. Index.Comunicación, 8, 129150.

- Heredia, R. (2016). Humor y discurso: una propuesta para el análisis de la protesta en YouTube. Lenguaje, 44(1), 83-109

- Herrero-Diz, P.; Ramos-Serrano, M.: y Nó, J. (2016). Los menores como usuarios creadores en la era digital: del prosumer al creador colaborativo. Revisión teórica 1972-2016. Revista Latina de Comunicación Social, 071, 1.301 - 1.322. DOI: 10.4185/RLCS-20161147 
- Hidalgo-Marí, T.; y Segarra-Saavedra, J. (2017). El fenómeno YouTuber y su expansión transmedia. Análisis del empoderamiento juvenil en redes sociales. (Spanish). Fonseca: Journal of Communication, (15), 43.

- Manso, J.; Ezquerra, Á.; Burgos, M.; y Mafokozi, J. (2019). Análisis del tratamiento de contenidos en la creación de audiovisuales educativos. Revista Eureka Sobre Enseñanza y Divulgación de Las Ciencias, 16(1), https://doi.org/10.25267/Rev_Eureka_ensen_divulg_cienc.2019.v16.i1.1 601

- Mateos, C.; y Sedeño, A. (2018). Videoartivismo: Poética del conflicto simbólico. Comunicar, 26(57), 49-58. https://doi.org/10.3916/C57-201805

- Márquez, I.; y Ardèvol, E. (2018) Hegemonía y contrahegemonía en el fenómeno youtuber. Desacatos, 56. 34-49.

- Meseguer, J. (2016). El increíble éxito de los youtubers. IEEM Revista de Negocios, 19(3), 88-91.

- Muñoz, B.. (2018). Análisis del involucramiento y la reconfiguración en YouTube México a partir del caso \#lady100pesos. Fonseca, Journal of Communication, 16, 155-170.

- Pérez, J. (2017). Mujeres en el videoclip: La representación de la mujer en los vídeos musicales de Diane Martel. Revista Prisma Social, № especial, 202-232.

- Pérez, J.; y Rodríguez-López, J. (2017). Edición del videoclip y duración del plano: análisis del montaje de "I Took a Pill in Ibiza" (Mike Posner). (Spanish). Doxa Comunicación, (25), 149 - 167. 
- Pérez-Rufí, J.P. (2018). Producción y edición del vídeo de bajo presupuesto: estudio de caso de "Lost Ones" (Joan Thiele) de Giada Bossi. (Spanish). Mediterranean Journal of Communication / Revista Mediterránea de Comunicación, 9(2), 291-303.

- Pérez-Torres, V.; Pastor-Ruiz, Y.; y Abarrou-Ben-Boubaker, S. (2018). Los youtubers y la construcción de la identidad adolescente. Comunicar, 55 (XXVI), 61-70.

- Rajas, M.; Puebla-Martínez, B.; y Baños, M. (2018). Formatos Audiovisuales Emergentes para Moocs: diseño informativo, educativo y publicitario. El profesional de la información, 27(2), 312-321. Recuperado de https://doi.org/10.3145/epi.2018.mar.09

- Rodríguez-Breijo, V.; Gallardo-Camacho, J. y Sierra-Sánchez, J. (2018). Información política en los vídeos que son tendencia en Youtube España. El profesional de la información, 27(5), 1041-1049. Recuperado de https://doi.org/10.3145/epi.2018.sep.08

- Roncallo Dow, S.; y Uribe-Jongbloed, E. (2017). La estética de los videoclips: propuesta metodológica para la caracterización de los productos audiovisuales musicales. Cuadernos de Música, Artes Visuales y Artes Escénicas, 12(1), 80-110. Recuperado de https://doi.org/10.11144/Javeriana.mavae12-1.evpm

- Rubio, M. (2017). El vídeo ciudadano toma las calles. El videoactivismo como nueva forma de resistencia. IC: Revista Científica de Información y Comunicación, (14), 257-262.

- Rubiano-Pinilla, E. (2017). La cultura de la conectividad: una historia crítica de las redes sociales. Palabra Clave, 20(2), 571-573. Recuperado de https://doi.org/10.5294/pacla.2017.20.2.12 
- Santo Padre, F. (2014). Mensaje del Santo Padre Francisco para las XLVIII jornada mundial de las comunicaciones sociales. Mensajes, Vaticano

- Youtube. (2019). Objetivo. Recuperado de: https://www.youtube.com/intl/es/yt/about/

- Valderrama, M. y Velasco, P. (2018). ¿Programando la creación? Una exploración al campo socio-técnico de YouTube en Chile. Cuadernos.Info, (42), 39-53. Recuperado de https://doi.org/10.7764/cdi.42.1370

- Varela, O. (2016). Educomunicación en la pantalla: modelo para el desarrollo de videoclases. Revista Virtual Universidad Católica Del Norte, (48), 15-32

- Vicente-Fernández, P.; Vinader-Segura, R. y Gallego-Trijueque, S. (2019). La comunicación de moda en Youtube: Análisis del género Haul en el caso de Dulceida. Revista Prisma Social, (24), 77-98.

- Vizcaíno-Verdú, A.; Contreras-Pulido, P.; y Guzmán-Franco, M. (2019). Lectura y aprendizaje informal en YouTube: El booktuber. Comunicar, 27(59), 95-104. Recuperado de https://doi.org/10.3916/C59-2019-09

- Zomeño, D.; y Blay-Arráez, R. (2017). Diseño de formatos informativos en las redes sociales dirigidos al público millennial. El caso del videonews de playground. El Profesional de la información, 26(6), 11841191. Recuperado de https://doi.org/10.3145/epi.2017.nov.17 